University of Wollongong

Research Online

Faculty of Business - Papers (Archive)

Faculty of Business and Law

$1-1-2018$

The role of public health advocacy in preventing and reducing gambling related harm: challenges, facilitators, and opportunities for change

Jennifer David

Deakin University, jd741@uowmail.edu.au

Samantha L. Thomas

Deakin University, slthomas@uow.edu.au

Melanie J. Randle

University of Wollongong, mrandle@uow.edu.au

Mike Daube

Curtin University, m.daube@curtin.edu.au

Susan Balandin

Deakin University, susan.balandin@deakin.edu.au

Follow this and additional works at: https://ro.uow.edu.au/buspapers

Part of the Business Commons

Research Online is the open access institutional repository for the University of Wollongong. For further information contact the UOW Library: research-pubs@uow.edu.au 


\title{
The role of public health advocacy in preventing and reducing gambling related harm: challenges, facilitators, and opportunities for change
}

\begin{abstract}
Background: Public health advocacy is important in preventing harm and promoting health in communities. There has been little research into public health advocacy strategies which address gambling related harms. This study aimed to identify the role of advocacy in gambling reform, challenges to gambling advocacy implementation, and strategies that could facilitate change.

Methods: Semi-structured qualitative interviews were conducted with a sample of 50 stakeholders with backgrounds in gambling policy, research, health promotion, and advocacy. Participants were asked about how advocacy could be used to address gambling harm, and the range of barriers and facilitators for effective advocacy responses. A constant comparative method of analysis was used on the data.

Results: While participants perceived that there was a role for advocacy in preventing and reducing gambling related harm, they discussed a range of challenges. These included restrictions associated with funding of research and services, the power of the gambling industry, and the role of stigma in preventing people with lived experience of gambling from speaking about their experiences. Participants also described a range of facilitators of public health advocacy approaches, including independent funding sources, reframing the 'responsibility' debate, developing opportunities and capacity for people with lived experience of harm, and developing broadly based coalitions to enable cohesive and consistent advocacy responses to gambling harm.

Conclusion: There is a clear role for public health advocacy approaches aimed at preventing and reducing gambling harm. Future research could identify how advocacy strategies may be implemented as a part of a comprehensive public health approach to gambling reform.

\section{Disciplines}

Business

Publication Details

David, J. L., Thomas, S. L., Randle, M., Daube, M. \& Balandin, S. (2019). The role of public health advocacy in preventing and reducing gambling related harm: challenges, facilitators, and opportunities for change. Addiction Research and Theory, 27 (3), 210-219.
\end{abstract}


1 The role of public health advocacy in preventing and reducing gambling

2 related harm: challenges, facilitators, and opportunities for change

4 Jennifer L. David. Deakin University, Geelong Australia. Centre for Population Health

5 Research, Faculty of Health. jdavid@deakin.edu.au

6

7 Samantha L. Thomas. Deakin University, Geelong Australia. Centre for Population

8 Health Research, Faculty of Health. samantha.thomas@deakin.edu.au

Melanie Randle. University of Wollongong, Wollongong Australia. School of

Management, Operations and Marketing, Faculty of Business. mrandle@uow.edu.au

Mike Daube. Curtin University, Perth Australia. Faculty of Health Sciences.

\section{M.Daube@curtin.edu.au}

Susan Balandin. Deakin University, Geelong Australia. Centre for Population Health

Research, Faculty of Health. susan.balandin@deakin.edu.au

Funding and Disclosure of Interests: Jennifer L David is the recipient of an Australian

Government Research Training Program Scholarship aligned with an Australian Research Council Discovery Grant. The data presented in this paper was collected within a larger piece study funded by the Victorian Responsible Gambling Foundation Competitive Grants Scheme. Associate Professor Samantha Thomas receives funding for gambling research from the Australian Research Council Discovery Grant Scheme, and the Victorian Responsible Gambling Foundation. In the last five years she has received funding for gambling harm prevention education from AFL Sportsready and the AFL Players Association. Associate Professor Melanie Randle receives funding for gambling research from the Victorian Responsible Gambling Foundation. Professor Mike Daube receives funding for gambling research from the Australian Research Council and the Victorian Responsible Gambling Foundation. Professor Susan Balandin receives funding from the Victorian Responsible Gambling Foundation. 
34 Corresponding Author: Jennifer L. David, Deakin University, Geelong Australia.

35 Centre for Population Health Research, School of Health and Social Development,

36 Faculty of Health. e. jdavid@deakin.edu.au

37 Approximate word count: 5134 excluding citations and reference list.

38 Abstract

39 Background: Public health advocacy is important in preventing harm and promoting health in communities. There has been little research into public health advocacy strategies that address gambling related harms. This study aimed to identify the role of advocacy in gambling reform, challenges to gambling advocacy implementation and strategies that could facilitate change.

Methods: Semi-structured qualitative interviews were conducted with a sample of 50 stakeholders with backgrounds in gambling policy, research, health promotion and advocacy. Participants were asked about how advocacy could be used to address gambling harm, and the range of barriers and facilitators for effective advocacy responses. A constant comparative method of analysis was used on the data.

Results: While participants perceived that there was a role for advocacy in preventing and reducing gambling related harm, they discussed a range of challenges. These included restrictions associated with funding of research and services, the power of the gambling industry, and the role of stigma in preventing people with lived experience of gambling from speaking about their experiences. Participants also described a range of facilitators of public health advocacy approaches, including independent funding sources, reframing the 'responsibility' debate, developing opportunities and capacity for people with lived experience of harm, and developing broadly-based coalitions to enable cohesive and consistent advocacy responses to gambling harm.

Conclusion: There is a clear role for public health advocacy approaches aimed at preventing and reducing gambling harm. Future research could identify how advocacy strategies may be implemented as part of a comprehensive public health approach to gambling reform. 
67 Keywords: Advocacy, Gambling, Public health 68 
71 The role of advocacy is a rapidly growing area of interest in gambling reform (Thomas et al. 2015). Although there have been numerous calls for the reform of the gambling industry and its products, popular approaches have predominantly used an addiction-oriented approach, focusing on personal responsibility strategies to minimise harm (Miller et al. 2014; Hancock and Smith 2017). However, there is a long tradition in public health of using a variety of advocacy strategies as part of a comprehensive approach to protect and promote positive health outcomes in communities (Moore et al. 2013). Successful public health interventions have been achieved as the result of strong scientific evidence, community support, and advocacy as the drivers of policy change (Chapman 2004a; Daube 2017). Such strategies are strongly linked to action, engaging communities, and creating robust arguments for change (Bassett 2003). Advocacy includes 'spreading the word' to the community and decision-makers about strategies and policies that need to be enacted to protect and promote the health of communities (Avery and Bashir 2003 p.1207), and persuading: (Moore et al. 2013 p.5)

90

Although there is no single formula for effective advocacy, a range of individual and collective strategies may facilitate successful campaigns (Jenkins 2006). Strategies can be grouped into five key approaches that are not necessarily mutually exclusive. 
94 First are strategies that seek to influence policy change through the use of sound scientific evidence to highlight harms, challenge existing policy, and push for policy reform (Cullerton et al. 2016; Elliott-Green et al. 2016; Cohen and Marshall 2017).

97 Second, is the development of strong coalitions and partnerships across agencies 98 (such as health and other professional organisations) united by a common goal, 99 which enable the fostering and use of explicit skill sets and greater access to a broader range of policy and decision-makers (Frieden 2014; Cullerton et al. 2016;

101 Cohen and Marshall 2017). Third, are strategies that seek to raise awareness and

102 frame the public debate about key issues, particularly through the development of

103 key messaging strategies and the use of the media (Chapman 2004b Freudenberg 104 2005; Gen and Wright 2013). Fourth, are strategies that aim to empower communities, by providing a strong voice for individuals who are marginalised or unable to speak for themselves (Dorfman and Krasnow 2014), educating communities about product harms (Freudenberg 2005; Chaloupka et al. 2011;

108 Brinsden and Lang 2015), and encouraging community participation in reform 109 initiatives (Cohen and Marshall 2017). Finally, are strategies that monitor and counter vested influences that seek to resist and create barriers when industry

111 reform efforts may be implemented (Chapman 2007; Jahiel and Babor 2007;

112 Thomas et al. 2015).

114 Along with documenting facilitators for advocacy, researchers have identified a number of issues that may create barriers to successful public health advocacy campaigns (Farrer et al. 2015; Cohen and Marshall 2017; Smith and Stewart 2017). 
118 First, public health advocates can encounter significant opposition to reform

119 agendas, particularly when advocating for policy change that conflicts with the socio-

120 cultural, political or economic interests of dominant social agencies, governments, or

121 industries (Andrews and Edwards 2004). Chapman (2004a) has commented that

122 public health advocates often encounter fraught and highly organised opposition to

123 change from a range of agencies:

“Opposition can come from governments, industry, community and religious interest groups, and from within the public health field itself." (Chapman 2004b

Second, are the challenges that arise from the commercial interests of large corporations, and the resourcing and influence that these bring. These include the ability of large organisations to influence governments through means such as using

132 political donations, paid lobbyists, and political advertising and campaigning

133 (Brownell and Warner 2009; Hawkins et al. 2012; Freudenberg 2014). In contrast, there are few resources for public health advocacy or translation initiatives, which arguably remain the 'poor cousin' within the public health field (Chapman 2001).

136 Corporate Social Responsibility (CSR) initiatives are another example of strategies

137 used by industries as a public relations tool, through the support of community 138 programs, donations to charities, and the provision of resources for youth initiatives

139 (Rosenberg and Siegel 2001; Lyness and McCambridge 2014; Richards et al. 2015).

140 When industries create positive perceptions in the community, and a reliance on

141 industry funding, it may be difficult for community organisations to move away from 
142 relationships with these companies, to advocate for the promotion of health (Jane and Gibson 2017).

145 Third, are the challenges resulting from funder influence over research (Chapman

146 2001; Livingstone and Adams 2016). For example, a recent study of funder influence

147 over published research outputs in a major addiction journal identified that around one third of authors $(n=117,36 \%)$ had experienced at least one incident of funder

149 interference in their research including the censorship of research findings, the

150 language used in reports, the writing of reports, and when and how findings were

151 released (Miller et al. 2017). Researchers have also explored government

152 suppression of health information in the Australian health sector, identifying that governments delayed or prohibited publications, using a range of methods of suppression that included blocking funding, delaying access to data, controlling report findings, and sanitising reports (Yazahmeidi and Holman 2007). Such suppression may impact on a researcher's ability to use scientific evidence to argue

157 for policy reform, or regulatory change.

159 Finally, there are the debates about whether and to what extent academics should

160 be involved in advocacy. Smith and Stewart (2017) identified a number of challenges

161 for academics engaging in advocacy, including the perceived ethical implications of

162 traditional researchers moving beyond their research findings to provide policy recommendations; a perception that involvement in advocacy initiatives was for ideological rather than empirically driven reasons; and concerns that continued involvement in advocacy might compromise perceptions of research independence

166 and credibility (Smith and Stewart 2017). Further to this is the concern that 
167 academics are often judged by conventional research outputs, but rarely by their broader impact (Mirvis 2009; Vale and Karataglidis 2016). This may ultimately limit

169 the involvement of academics in policy development (Lauder 2014).

171 How then do those who wish to engage in advocacy in the area of gambling

172 negotiate their way through the range of challenges and facilitators to effective

173 advocacy initiatives? In particular, how does this occur when there is significant

174 opposition from vested interests? Although the shift to a public health approach to

175 gambling reform is gaining momentum, researchers have documented significant

176 barriers to this, including challenges in producing scientific research (Adams 2011;

177 Cassidy et al. 2013). Utilising qualitative interviews with an international sample of 178 health promotion workers, researchers, policy makers, and advocates working in gambling harm reduction and prevention, we posed three research questions:

1. What are the challenges and facilitators to effective advocacy initiatives?

2. Which strategies are most effective in countering opposition, and building feasible methods for change?

3. What role can advocacy play in reducing and preventing gambling related

\section{Methods}


191 The data presented in this paper was collected within a broader study of the range of

192 issues contributing to the normalisation of gambling (Thomas et al. in press). The

193 present study specifically explored questions regarding the role of advocacy in

194 gambling harm prevention and reform. Constructivist Grounded Theory (CGT)

195 methods were used in the creation of research questions, data collection and

196 analysis (Charmaz 2006). CGT recognises the subjective nature of data collection

197 and analysis, the interactions between study participants and researchers, and how

198 the researcher is situated within the interpretation of study data (Charmaz and

199 Belgrave 2012). The use of CGT methods resulted in an interpretive data analysis

200 and descriptive presentation of study findings (Charmaz and Belgrave 2012).

201

202

Sample selection and recruitment

203

204 To guide the sample selection for this study, we used the stakeholder categories

205 outlined in the Australian National Preventive Health Agency Stakeholder

206 Engagement Strategy, which included those working in health promotion, academia

207 or research, government and policy, and in non-governmental organisations,

208 including peak bodies and advocacy organisations (Australian National Public Health

209 Agency 2012). To recruit participants, the research team constructed a list of

210 potential participants in each of the categories, based on their existing networks in,

211 and, knowledge of the field. The team also scanned websites for additional

212 researchers and health promotion and non-government organisations involved in

213 gambling harm prevention activities. Participants were initially approached by email,

214 with snowball-sampling techniques (Sadler et al. 2010) employed to identify

215 additional participants, particularly from countries outside Australia. Ethical approval 
216 was received from the University Human Research Ethics Committee (HEAG-H

217 01_2016).

219 Data collection

221 The questions relating to advocacy within the interview schedule focused on three key themes of inquiry: the role of advocacy in gambling reform; perceived challenges or facilitators for advocacy; and previously successful advocacy efforts in gambling harm reduction. Five researchers, including the first and second authors conducted semi-structured interviews lasting on average 60 minutes. These interviews were conducted via telephone or Skype and audio-recorded with the permission of participants. Consistent with qualitative methods (Miles and Huberman 1994) as the data were collected and analysed, the interview schedule was modified to reflect new and emerging issues raised by participants.

Data analysis

233 After transcription of the interviews, all data were de-identified to ensure anonymity

234 of participants, QSR NVivo 10 was used to manage the data. Using a thematic 235 analysis approach (Miles and Huberman 1994) the first author led the data analysis 236 process. Each transcript was read, re-read and coded to establish the themes and sub-themes emerging from the data relevant to the research questions. Using a process of open coding, emerging themes and sub themes were compared across the data to enable the identification of any patterns in participant responses. Authors

240 read the transcripts and engaged in multiple detailed discussions about the 
241 interpretation of emerging themes and sub-themes, and, the similarities and

242 differences in responses. The authors regularly returned to study the research

243 questions and advocacy theory to interpret responses. In instances where the

244 authors differed in their interpretation, transcripts were again reviewed and analysed,

245 with discussions between the authors occurring until consensus was reached and

246 the final themes and subthemes were agreed. While qualitative research does not

247 seek to provide numerical values to data, in reporting the results of the data we

248 indicate 'a few' to represent less than $25 \%$ of participants, 'some' as up to $50 \%$,

249 'many' as up to $75 \%$, and 'most' as over $75 \%$ agreement.

250

251 Results

252

253 A total of 50 participants were interviewed. Although participants were from eight 254 countries, over half were from Australia $(n=32)$. Participants came from a range of 255 professional backgrounds, which were grouped into four categories: 1) academics 256 and researchers $(n=19), 2)$ health promotion organisations $(n=16), 3)$ advocacy, not

257 for profit, and peak bodies ( $n=10)$, and 4) government organisations and policy

258 makers $(n=5)$.

259

260

261

262

263

264 
Table One

Overview of background of study participants

\begin{tabular}{|l|c|c|c|c|c|}
\hline Field & $\begin{array}{l}\text { Academia } \\
\text { and/or } \\
\text { research }\end{array}$ & $\begin{array}{l}\text { Health } \\
\text { promotion } \\
\text { organisations }\end{array}$ & $\begin{array}{l}\text { Advocacy, } \\
\text { not for profit } \\
\text { and peak } \\
\text { bodies }\end{array}$ & $\begin{array}{l}\text { Government } \\
\text { organisations } \\
\text { and policy } \\
\text { makers }\end{array}$ & Total \\
\hline Australia & 9 & 13 & 6 & 4 & 32 \\
\hline $\begin{array}{l}\text { New } \\
\text { Zealand }\end{array}$ & 2 & 2 & 1 & 1 & 6 \\
\hline $\begin{array}{l}\text { United } \\
\text { States of } \\
\text { America }\end{array}$ & 2 & 0 & 3 & 0 & 5 \\
\hline Canada & 2 & 0 & 0 & 0 & 2 \\
\hline $\begin{array}{l}\text { United } \\
\text { Kingdom }\end{array}$ & 2 & 0 & 0 & 0 & 2 \\
\hline Sweden & 1 & 0 & 0 & 0 & 1 \\
\hline Finland & 1 & 0 & 0 & 0 & 1 \\
\hline Ireland & 0 & 1 & 0 & 0 & 1 \\
\hline Total & 19 & 16 & 10 & 5 & 50 \\
\hline
\end{tabular}

270 Participants described a range of challenges to the implementation of effective advocacy initiatives, and strategies to overcome these challenges.

Responding to the influence of the gambling industry

275 The first theme related to the influence and power of the gambling industry and the difficulties this created for advocating for comprehensive reduction and prevention

277 strategies. While a range of industry influences were described, the potential

278 influences over political decision making, research, and the framing of the public

279 debate about gambling provided the three biggest challenges for advocates. Some

280 participants described the powerful mechanisms used by industry to influence

281 government policy. These included making political donations, lobbying politicians,

282 and having a seat at the policy making table. Some participants perceived that these 
283

284

285

286

287

288

289

290

291

292

293

294

295

296

297

298

299

300

301

302

303

304

305

306

307

mechanisms led to the development of government policy and legislation that were 'sympathetic' to the industry, and that undermined the ability of public health advocates to convince governments to implement evidence-based reforms to reduce gambling harm. One participant described how the power of political donations and lobbying limited the ability of advocates to influence political decision-makers, and argue for evidence-based reform:

“...trying to convince government when there's significant money that flows to political parties and politicians from the industry makes it much tougher for people campaigning and seeking reasonable reforms." - Participant 20, Policy

Participants also described the role of industry in influencing research funding agendas, and in directly (or indirectly) funding academic research. This included having input into the setting of priorities for research funding agendas. Participants particularly described the role of industry in raising money for research, sponsoring academic conferences, and indirectly funding treatment services. One participant stated that while the gambling industry did not necessarily seek to control or co-opt research, it ensured that research supported its agenda:

"So, it's not the co-opting of research. It's rather disproportionately funding research people and research areas that support their story." - Participant 4, Academics/Researchers

This provided a challenge for public health researchers and advocates who reported that the involvement of industry in research, or research agenda setting, meant that 
308 there was limited critique of industry practices and how to counter these. Some

309 participants also noted that direct or indirect funding of research and treatment

310 services by industry made it very difficult for researchers and services to speak out

311 about the harms perpetuated by the gambling industry and its products. Describing

312 the role of treatment providers, one participant commented:

313

314

Developing clear advocacy messages, and reframing the public debate

"So, they're very torn; yes, they want to be rid of them (pokies), no, they don't want to lose funding, and so they end up not doing anything." - Participant 8, Health Promotion

Some described the important role of independent funding sources in enabling researchers and services providers to persuade decision makers of the need for regulatory reform of the industry and its products. Participants acknowledged that independent funding for academic research, treatment services, and community groups was important in ensuring that messages about reform were not misrepresented:

"I think the other thing is independence, so the ability to actually frame issues and raise issues from the local level without those issues being watered down, or filtered down, or disrupted." - Participant 36, Academics/Researchers 
332 Participants discussed how the financial capacity of the gambling industry enabled it

333 to run effective campaigns to frame the debate about problem gambling and to

334 challenge reform initiatives. Some commented that the industry had been very

335 effective in framing problem gambling as an issue relating to personal responsibility.

336 Some participants described the 'very smart PR and marketing departments' that

337 were engaged by the gambling industry, and their ability to mount 'sophisticated

338 campaigning' strategies. One participant noted that the lack of resources available to

339 advocates was a significant limitation in advocacy initiatives:

"If the gambling industry can advertise, and the government can advertise, and the advocacy groups don't have any money to do anything like that, that's a severe limitation... it all comes down to resources." - Participant 41,

Many participants noted the importance of reframing discourse about problem gambling away from individual responsibility and towards the health and social costs of gambling harm. This included reframing gambling related harm as a public health issue, rather than a political or economic issue:

"They need to continue to talk about the harms. They need to continue to talk to the government about their role in this as a health issue, a public-health issue, and try to get the government to stop only looking at it from an economic point of view....and, oh, to stop framing the problem gambling as an individual's problem." - Participant 28, Health Promotion 
357 Some believed that the most effective way of overcoming these resource limitations

358 was effective engagement with the media. Participants noted that media-based

359 advocacy enabled a broad reach of messages to key target audiences. These had

360 impact because governments and the gambling industry were often responsive to

361 what was 'said in the media':

362

"It's only when the public gets really upset with the way in which gambling's being delivered and it threatens a politician's likelihood of being re-elected things are going to change...So media is very, very important." - Participant 4, Academics/Researchers

Participants also noted that there was a critical need for independent (i.e. not aligned with the gambling industry or government) peak bodies on gambling harm, which would serve as 'umbrella organisations' which could help to reframe the public debate about gambling, and to drive reform. For example, one participant identified the Alliance for Gambling Reform (an Australian based coalition of local councils, churches, and other community organisations concerned about the harms associated with gambling) as a key driver in reframing the debate about gambling related harm towards problematic gambling products. Others commented that in the absence of these peak bodies, researchers, local government, and community organisations should build and consolidate their networks to work together for change in local communities. In particular, participants described the need for open, transparent, consultation about gambling reform: 
"We need a national response and strategy to gambling in Australia that is evidence-informed and treats it as a health and social issue in terms of public health. Whenever we have a discussion about gambling, we need to include research, academia, treatment and people who consume gambling products to ensure that we have an open consultative process about this harmful product." - Participant 43, Health Promotion

\section{Overcoming ideological differences relating to the role of advocacy}

The third theme related to ideological differences between individuals and groups about advocacy strategies, and the goals and aims of advocacy. While there was general agreement that advocacy was needed from participants from a range of professional backgrounds, participants particularly commented on the ideological differences relating to the involvement of academics in advocacy. A few participants questioned whether academics should have, or felt comfortable with, a role in advocacy. One participant commented that academics did not 'like to consider' themselves advocates, that research needed to be purely empirically driven, and that agendas ran the risk of being motivated 'purely by ideology' and 'not evidence'.

Others were concerned about the impact of the involvement in advocacy on the reputations of academics, with a few commenting that when researchers became involved in advocacy their work was often 'tarnished as unscientific', or that their objective could be described as 'propaganda'.

Despite this, many participants both within and outside academia believed that academics had an important role in advocacy initiatives that aimed to influence 
406 policy and decision makers. Participants noted, that it was important for independent

407 evidence generated by academics to be effectively disseminated to local groups to

408 be used in their advocacy campaigns, and that it was important for this evidence to

409 be shared in 'an easily digestible format that is reliable and valid and easily

410 accessible...'

411

412 Building coalitions and working towards a common goal

413

414 The fourth challenge for advocacy initiatives related to getting diverse groups of

415 individuals to work together toward a common goal of addressing gambling harm.

416 Some participants stated that one of the challenges associated with advocacy

417 initiatives was that while many individuals had advocated for gambling reform,

418 gambling reform would not be achieved when individuals worked alone or in small

419 groups. One participant stated that a key difficulty with current advocacy initiatives

420 was getting individuals to come together and advocate for reform without getting

421 people 'offside':

422

423

"If you have lots of individuals coming together they all have their own story,

424 their own idea. How do you then drive that to one common goal, and how do you then get access to the people that you need to get access to in a way that you're not going to get them offside?" - Participant 45, Health Promotion

428 Participants commented that in order for meaningful reform to occur, academics, local councils, community groups, and sporting organisations needed to work

430 together to convince decision makers to enact change. One participant noted that 
431 advocacy initiatives needed to be targeted toward governments, with a wide range of

432 groups coming together to argue for change. Participants commented that 'working together' and 'trying to work collaboratively' was key to successful advocacy. Some participants considered that shifting to a public health approach for the prevention of gambling harm would enable the development of coalitions. This was because effective approaches to gambling reform would depend on getting the philosophy right... a turnaround of the ideology... this is the only thing that will really make a difference'. Overall, participants argued for a clear shift in advocacy initiatives towards a focus on harmful products:

"I think there's an acceptance now that we need to look at population level effects and that we need to look at the product and move away from the individual responsibility." - Participant 27, Academics/Researchers

\section{Engaging communities and those with a lived experience of harm}

447 Finally, were the challenges associated with engaging those with a lived experience of gambling harm, and local communities, in advocacy initiatives. Participants observed how the stigma associated with 'problem gambling' meant that potential advocates feared that such stereotypes might 'jeopardise' their jobs, relationships and result in negative judgments from others. This was a critical factor in 'whether or not people decided to be involved' in advocacy. Stigma extended beyond the individual, with family and friends also concerned about the negative impacts of people speaking out. Yet, participants acknowledged that encouraging individuals to speak out played a crucial role in achieving gambling reform. Participants 
commented on the need to empower individuals with a lived experience of gambling harm to be involved in advocacy, arguing that those who had a lived experience of gambling harm, and their friends and families, were the most 'authentic advocates for policy reform'. Participants suggested a range of initiatives that would encourage

460 people with a lived experience of gambling harm to make a contribution to the debate about gambling reform. This included strategies such as advocacy and media training to enable the communication of the most up to date evidence about gambling related harm. As one participant stated: "There's nothing more powerful than hearing a personal story from somebody

Finally, some participants discussed the importance of 'firsthand knowledge', the need to build a 'groundswell' of support to advocate for gambling reform, and the power of grassroots movements in providing a voice for those who struggled to be heard:

“...people who have less power and agency within society are always going to struggle to be heard. There's the classic people who need the most advocacy always struggle to advocate for themselves because they don't have the social capital to do that and the knowledge and the networks." - Participant 19,

\section{Discussion}


481 Although public health advocacy has previously been critical in reform on significant 482 public health issues such as tobacco control (Chapman 2004a; Daube 2017), there 483 has been limited discussion about how public health advocacy can address 484 gambling-related harms (Thomas et al. 2015). The results of this study highlight that 485 while no one clear advocacy strategy has been implemented across stakeholder 486 groups, participants are actively engaging in advocacy associated with gambling harm reduction and prevention. However, this advocacy is fragmented in its implementation. The creation of a clear pathway or 'road map' is necessary to unite public health and other advocates and implement effective public health advocacy

490 initiatives. This study provides the starting point for constructing this road map.

492 A number of challenges, facilitators and effective strategies for advocacy responses 493 in gambling harm reduction and prevention were identified in this study. Some of 494 these challenges centred on the power of the gambling industry, which was 495 perceived by participants as affecting all aspects of the advocacy process. These 496 include potential conflicts of interest between organisations who would like to be 497 involved in advocacy and their funding sources, donations to political groups, the 498 distortion of evidence and influence over research priority setting. Similar issues 499 have been identified in relation to other unhealthy commodity industries such as 500 tobacco, junk food and alcohol (Brownell and Warner 2009; Freudenberg 2014;

501 Brinsden and Lang 2015). The World Health Organization (WHO) (2003) has sought 502 to address tobacco industry interference through mechanisms such as the WHO 503 Framework Convention on Tobacco Control (FCTC), which commits all 181 504 signatory governments to protect their tobacco control policies from the political 505 influence of the tobacco industry (WHO 2003). Given the globalisation of gambling 
506 products (Hellman et al. 2017), conventions such as the FCTC may also play a key

507 role in reducing gambling harm. The FCTC focuses on the implementation of evidence-based strategies that can reduce the demand for tobacco products, the

509 regulation of products, the supply of these products, education, and advertising

510 restrictions. Research indicates that many of these strategies are used by the

511 gambling industry to promote their products and to resist regulatory reform (Thomas

512 et al. 2017). National and international conventions may support the development of

513 clear strategies aimed at preventing and reducing gambling harm.

515 A number of other advocacy challenges identified focused on practical limitations.

516 Inadequate distribution of resources often limits advocates' ability to implement

517 effective strategies. Also apparent were the difficulties associated with different

518 groups working together for a common goal. Coalitions are known to be important in

519 bringing a variety of voices together and have been critical in the development of

520 effective advocacy responses in other areas of public health (Douglas et al. 2015;

521 Cullerton et al. 2016; Weishaar et al. 2016), such as the successful implementation

522 of a range of tobacco free policies (Douglas et al. 2015; Weishaar et al. 2016). It was

523 clear from participants' responses that the development of gambling advocacy

524 coalitions is critical in creating successful initiatives. However, those working to

525 address gambling harm were often seen as appearing to focus on targeted, specific

526 advocacy responses, rather than 'big picture' approaches. For example, advocacy

527 initiatives were seen as often being reactive to single issues such as the regulation

528 of gambling advertising in live sport, or specific behaviours associated with industry.

529 Further, there is limited measurement of or reflection on the success of advocacy

530 initiatives. At present there are few initiatives that take a long term, proactive focus 
531 on bigger issues that would significantly prevent or reduce gambling related harm. In

532 a previous paper we have argued that such big picture approaches would include

533 embedding advocacy strategies into broader planning for public health initiatives,

534 and developing coalitions with advocates working to reform other harmful industries

535 (Thomas et al. 2015). Further steps should include development of a 'road map' to

536 guide advocacy strategies, identify any commonalities with other public health issues

537 (e.g. the advertising of products in sporting matches), and potential coalitions. As argued by participants in this study, this road map could be constructed within broader national or international public health strategies or international conventions.

541 The engagement of those with a lived experience of gambling harm is important in highlighting issues by incorporating a human element with which people can identify (Jernigan and Wright 1996; Thomas et al. 2015). Given research that has highlighted

544 the importance of the lived experience in successful advocacy initiatives (Holder and

545 Treno 1997), the stigmatisation of individuals and their families who have experienced harm from gambling is an important issue to address. It is notable that engagement in advocacy for those with a lived experience of gambling harm will not necessarily involve talking to the media. Media advocacy is not for everyone, and people with a lived experience may wish to be involved in activities that do not

550 involve recounting their experience. Organisations should therefore seek to provide a 551 range of training and advocacy opportunities for those directly impacted by gambling 552 harm, including individuals, their families, and communities. Some organisations have started to consider how to include people with a lived experience in advocacy.

554 For example, the Champions for Change program in Australia (Alliance for Gambling 555 Reform 2018) includes a range of participation options for people with a lived 
experience of gambling harm, including engaging with the media, speaking to politicians and/or policy makers, engaging with the public and community groups, volunteering, and promoting venues that do not contain poker machines.

560 Although current strategies to address gambling harm have predominantly focused

561 on individual responsibility approaches, it is clear that there is a need to challenge

562 this framing and present gambling harm as a broader public health issue. The use of

563 individual responsibility rhetoric is a tactic known to be used by other unhealthy

564 industries such as tobacco. Research has demonstrated that this framing deflects

565 perceptions of harm away from products or industry practices and creates concern

566 amongst the public regarding freedom of choice (Moodie et al. 2013; Friedman et al.

567 2015). In addressing this, discussions about the causes of gambling harm need to continue to reiterate the society wide impact of gambling harm, while clearly linking this harm to a range of determinants, including gambling product and industries.

571 Participants also spoke of some ideological challenges to effective advocacy.

572 Advocacy is perceived as a strategic approach to advance social or public policy

573 objectives, usually by organisations, whereas, personal activism can take more

574 direct and less planned forms. Notwithstanding the overlaps in these definitions, and

575 some confusion about the differences, what is important is the recognition that

576 advocacy is essential in the creation of harm reduction and prevention strategies in

577 gambling. Ensuring that advocacy is evidence based and that independent funding is

578 available for research and services, and providing opportunities for academics to 579 publish articles in journals which support researchers discussing the implications of 
580 their research for policy and practice, may help to dispel some of the myths associated with engagement in advocacy.

582

583 Consequently, this raises the question of how to create and develop feasible public

584 health advocacy responses to address gambling harm. These responses are 585 pictorially illustrated in Figure One.

586

587 First, there is the need to develop and enable advocates, which could be done with a combination of different strategies. In the area of gambling, there is concern about the role of stigma in preventing individuals, particularly those with a lived experience

590 of gambling harm, being involved in advocacy. It is therefore critical that those working in public health are mindful of the potential for stigma to occur when developing future advocacy campaigns and initiatives. Further, those mechanisms that enable community participation in advocacy by providing supportive environments (Flynn 2015) require consideration. For example, the creation of environments where healthy food choices were encouraged was critical in the effective implementation of sugar-sweetened beverage levies (soda taxes), where community driven advocacy was central to policy reform (Grumbach et al. 2017).

There is a need to challenge the structural barriers created by industry influence. In

600 public health there is a growing body of literature that argues that researchers should not accept funding from the industries they are studying (Stuckler and Nestle 2012;

602 Chew et al. 2014). This would help ensure that researchers' ability to advocate is 603 uninhibited. Smith and Stewart (2017) suggest that by creating a collaborative 604 environment, researchers could indirectly involve themselves in advocacy efforts 
605 (Smith and Stewart 2017). Given the inherent conflict of interest created by industry

606 being involved in research (Adams et al. 2010; Cowlishaw and Thomas 2018), it is

607 clear that using alternative funding sources would be one way to address this

608 conflict.

609

610 Finally, there is a need to consider how best to use limited resources to create

611 broadly based and consistent advocacy responses. Other industries (e.g. tobacco)

612 have successfully promoted their products and prevented reform using consistent

613 advocacy strategies (Menashe and Siegal 1998; Saloojee and Dagli 2000). A key

614 component to the success of coalitions in other areas of public health has been the

615 development of social capital (Dean and Gilbert 2009; Ogden et al. 2013). By

616 building social capital among advocates for gambling reform - developing

617 relationships with community members, government, academics, and researchers - it

618 could be possible to create strong connections, and subsequently coalitions that can

619 develop strategies, advocate for and ultimately implement gambling reform

620 initiatives. It is important that strong, respected and informed public health leaders

621 take a leading role in the coordination of coalitions.

622

\section{INSERT FIGURE ONE}

625 This study has a number of limitations. First, the initial recruitment of participants 626 included recruitment and referral from those among the researcher's networks, which

627 contributed to the higher participation from individuals based in Australia. Second,

628 although this study has a large sample size for a qualitative research study, it

629 focuses on a specific group of individuals who were working predominantly in areas 
630 of gambling reform. Thus, the study cannot be generalised to all individuals working

631 in gambling research, policy, or practice. A larger sample of international

632 participants, including those who work with or receive funding from industry, would

633 provide a broader picture of attitudes across the gambling field. Given both the

634 exploratory nature and specific focus of this study, more in-depth consultations with

635 stakeholders should now be used to build a road map of specific public health

636 advocacy strategies, which are relevant to different geographic or cultural contexts.

637 Consensus among stakeholders could identify what feasible and realistic advocacy

638 strategies for gambling harm should look like, including establishing (and

639 implementing) evidence-based priority areas in relation to the reduction and

640 prevention of gambling harm.

641

\section{Conclusion}

643

644 There is a role for advocacy in future gambling harm reduction and prevention

645 strategies. However, a number of key challenges need to be overcome for this to

646 occur. Those working in public health could explore ways of addressing these

647 challenges, learning from experience in advocacy on other public health issues, and

648 consider how to create comprehensive and feasible strategies to facilitate public

649 health advocacy in gambling with a continuing focus on clear and consistent

650 messages, coalitions and community engagement.

651

652 Abbreviations

653 CGT: Constructivist Grounded Theory

654 CSR: Corporate Social Responsibility 
655 FCTC: Framework Convention on Tobacco Control

656 WHO: World Health Organization

\section{Declarations}

\section{$658 \quad$ Ethical approval}

659 Ethical approval was obtained from Deakin University Human Research Ethics

660 Committee. Participants provided written and/or oral consent prior to participating in

661 the study.

\section{Consent for publication}

663 All participants consented to the data being used for publications.

\section{Availability of data and material}

665 This data will not be made available to ensure the privacy and anonymity of the 666 study participants.

\section{Funding and disclosure of interest}

668 Jennifer L David is the recipient of an Australian Government Research Training

669 Program Scholarship aligned with an Australian Research Council Discovery Grant.

670 The data presented in this paper was collected within a larger piece study funded by

671 the Victorian Responsible Gambling Foundation Competitive Grants Scheme.

672 Associate Professor Samantha Thomas receives funding for gambling research from

673 the Australian Research Council Discovery Grant Scheme, and the Victorian

674 Responsible Gambling Foundation. In the last five years she has received funding

675 for gambling harm prevention education from AFL Sportsready and the AFL Players

676 Association. Associate Professor Melanie Randle receives funding for gambling

677 research from the Victorian Responsible Gambling Foundation. Professor Mike

678 Daube receives funding for gambling research from the Australian Research Council 


\section{Authors' contribution}

JD was the lead researcher; she contributed to data collection and led data analysis and prepared the first draft and critical revisions of the paper. ST was the Chief Investigator and conceptualised the study, contributed to initial data collection, analysis and interpretation and, prepared the first draft and critical revision of the paper. MR and MD were study investigators and contributed to data interpretation, writing and critical revision of the paper. SB contributed to critical revision of the paper.

\section{Acknowledgements}

We would like to acknowledge Miss Hannah Pitt, Miss Amy Bestman and Miss Emily would also like to acknowledge the stakeholders who participated in this study.

\section{References}

Adams PJ. 2011. Ways in which gambling researchers receive funding from gambling industry sources. International Gambling Studies. 11(2):145.

697

Adams PJ, Buetow S, Rossen F. 2010. Vested interests in addiction research and policy poisonous partnerships: health sector buy-in to arrangements with government and addictive consumption industries. Addiction (Abingdon, England). 105(4):585.

Alliance for Gambling Reform. 2018. Champions for Change. [accessed 27 May 2018]. http://www.pokiesplayyou.org.au/champs_for_change.

Andrews KT, Edwards B. 2004. Advocacy organizations in the US political process. Annu Rev Sociol. 30:479-506.

Australian National Public Health Agency. 2012. Stakeholder Engagement Strategy. [accessed 11 Nov 2017]. http://webarchive.nla.gov.au/gov/20141217080018/http://health.gov.au/internet/anpha/publis hing.nsf/Content/stakeholder-engagement-strategy. 
Avery B, Bashir S. 2003. The road to advocacy — searching for the rainbow. American Journal of Public Health. 93(8):1207-1210.

Brinsden H, Lang T. 2015. An introduction to public health advocacy: reflections on theory and practice. Food Reserach Collaboration Policy Brief.

Brownell KD, Warner KE. 2009. The perils of ignoring history: big tobacco played dirty and millions died. how similar is big food? The Milbank Quarterly. 87(1):259-294.

Cassidy R, Lossouarn C, Pisac A. 2013. Fair Game: producing gambling research - The Goldsmiths Report London: Goldsmiths, University of London.

Chaloupka FJ, Powell LM, Chriqui JF. 2011. Sugar-sweetened beverages and obesity: the potential impact of public policies. Journal of Policy Analysis and Management. 30(3):645655.

Chapman S. 2001. Advocacy in public health: roles and challenges. International Journal of Epidemiology. 30(6):1226-1232.

Chapman S. 2004a. Advocacy in action: extreme corporate makeover interruptus: denormalising tobacco industry corporate schmoozing. Tobacco control. 13(4):445-447.

Chapman S. 2004b. Advocacy for public health: a primer. Journal of Epidemiology and Community Health (1979-). 58(5):361-365.

Chapman S. 2007. Chapter 4, Dead customers are unprofitable customers: potential and pitfalls in harm reduction and product regulation. Public health advocacy and tobacco control: making smoking history. p. 76-128.

Charmaz K. 2006. Constructing grounded theory: a practical guide through qualitative analysis (Introducing Qualitative Methods Series).

Charmaz K, Belgrave L. 2012. Qualitative interviewing and grounded theory analysis. The SAGE handbook of interview research: the complexity of the craft. Thousand Oaks, California: SAGE Publications, Inc.; p. 347-365.

Chew M, Brizzell C, Abbasi K, Godlee F. 2014. Medical journals and industry ties. Vol. 349. BMJ (Clinical research ed.).

Cohen BE, Marshall SG. 2017. Does public health advocacy seek to redress health inequities? a scoping review. Health and Social Care in the Community. 25(2):309-328.

Cowlishaw S, Thomas SL. 2018. Industry interests in gambling research: Lessons learned from other forms of hazardous consumption. Addictive behaviors. 78(Supplement C):101106. 
Cullerton K, Donnet T, Lee A, Gallegos D. 2016. Playing the policy game: a review of the barriers to and enablers of nutrition policy change. Public Health Nutrition. 19(14):26432653.

Daube M. 2017. Democracy is not a spectator sport: 11 commandments for public health advocacy [accessed 27 May 2018]. https://croakey.org/longread-democracy-is-not-aspectator-sport-11-commandments-for-public-health-advocacy/.

Dean L, Gilbert KL. 2009. Social capital and political advocacy for African American health. Harvard Journal of African American Public Policy. 16:85-95.

Dorfman L, Krasnow ID. 2014. Public health and media advocacy. Annual Review of Public Health. 35:293-306. eng.

Douglas MR, Manion CA, Hall-Harper VD, Terronez KM, Love CA, Chan A. 2015. Case studies from community coalitions. American Journal of Preventive Medicine. 48(1):S29S35.

Elliott-Green A, Hyseni L, Lloyd-Williams F, Bromley H, Capewell S. 2016. Sugarsweetened beverages coverage in the British media: an analysis of public health advocacy versus pro-industry messaging. BMJ Open. 6(7).

Farrer L, Marinetti C, Cavaco YK, Costongs C. 2015. Advocacy for health equity: a synthesis review. Milbank Quarterly. 93(2):392-437.

Flynn MAT. 2015. Empowering people to be healthier: public health nutrition through the Ottawa Charter. The Proceedings of the Nutrition Society. 74(3):303-312.

Freudenberg N. 2005. Public health advocacy to change corporate practices: implications for health education practice and research. Health Education \& Behavior. 32(3):298-319.

Freudenberg N. 2014. Lethal but legal: corporations, consumption, and protecting public health. Oxford University Press.

Frieden TR. 2014. Six components necessary for effective public health program implementation. American Journal of Public Health. 104(1):17-22.

Friedman LC, Cheyne A, Givelber D, Gottlieb MA, Daynard RA. 2015. Tobacco industry use of personal responsibility rhetoric in public relations and litigation: disguising freedom to blame as freedom of choice. American Journal of Public Health. 105(2):250-260.

Gen S, Wright AC. 2013. Policy advocacy organizations: a framework linking theory and practice. Journal of Policy Practice. 12(3):163-193.

Grumbach K, Vargas RA, Fleisher P, Chung L, Liu W, Schmidt LA, Aragón TJ, Chawla C, Jones P, Yant A et al. 2017. Achieving health equity through community engagement in translating evidence to policy: the San Francisco health improvement partnership, 2010-2016. 809 
810 Hancock L, Smith G. 2017. Critiquing the Reno Model I-IV international influence on

811 regulators and governments (2004-2015) — the distorted reality of "responsible gambling" .

812 International Journal of Mental Health and Addiction. 15(6):1151-1176.

813

814

Hawkins B, Holden C, McCambridge J. 2012. Alcohol industry influence on UK alcohol

815

816 policy: a new research agenda for public health. Critical Public Health. 22(3):297-305.

Hellman M, Örnberg JC, Livingstone C. 2017. Gambling policy studies: a field that is growing in size and complexity. Addiction Research \& Theory. 25(6):433-435.

Holder HD, Treno AJ. 1997. Media advocacy in community prevention: news as a means to advance policy change. Addiction. 92(s2):S189-S199.

Jahiel RI, Babor TF. 2007. Industrial epidemics, public health advocacy and the alcohol industry: lessons from other fields. Addiction. 102(9):1335-1339.

825

Jane B, Gibson K. 2017. Corporate sponsorship of physical activity promotion programmes: part of the solution or part of the problem? The Journal of Public Health (Oxf).1-10. eng.

Jenkins GL. 2006. Chapter 13, Nonprofit organisations and political advocacy. In: Powell W,

830 Steinberg, R editor. The nonprofit sector: A research handbook. 2 ed. New Haven, CT:

831 Harvard University Press; p. 307-322.

832

833

834

835

836

Jernigan DH, Wright PA. 1996. Media advocacy: lessons from community experiences. Journal of Public Health Policy. 17(3):306-330.

Lauder H. 2014 Research impact: how academics can grab policy makers' attention. The Guardian. [accessed 22 March 2017]. https://www.theguardian.com/higher-educationnetwork/2014/nov/11/academics-grab-policy-makers-attention.

Livingstone C, Adams PJ. 2016. Clear principles are needed for integrity in gambling research. Addiction. 111(1):5-10.

Lyness SM, McCambridge J. 2014. The alcohol industry, charities and policy influence in the UK. The European Journal of Public Health. 24(4):557-561.

Menashe CL, Siegal. 1998. The power of a frame: an analysis of newspaper coverage of tobacco issues-United States, 1985-1996. Journal of Health Communication. 3(4):307-325.

Miles MB, Huberman AM. 1994. Qualitative data analysis: an expanded sourcebook.

850 Thousand Oaks: SAGE Publications, Inc.

Miller HE, Thomas SL, Robinson P, Daube M. 2014. How the causes, consequences and solutions for problem gambling are reported in Australian newspapers: a qualitative content analysis. Australian and New Zealand Journal of Public Health. 38(6):529-535.

Miller PG, Martino F, Gross S, Curtis A, Mayshak R, Droste N, Kypri K. 2017. Funder interference in addiction research: an international survey of authors. Addictive Behaviours. 72:100-105. 
860

861

862

863

864

865

866

867

868

869

870

871

872

873

874

875

876

877

878

879

880

881

882

883

884

885

886

887

888

889

890

891

892

893

894

895

896

897

898

899

900

901

902

903

904

905

906

907

908

909

Mirvis DM. 2009. From research to public policy: an essential extension of the translation research agenda. Clinical and Translational Science. 2(5):379-381.

Moodie R, Stuckler D, Monteiro C, Sheron N, Neal B, Thamarangsi T, Lincoln P, Casswell S, Lancet NCDAG. 2013. Profits and pandemics: prevention of harmful effects of tobacco, alcohol, and ultra-processed food and drink industries. Lancet. 381(9867):670.

Moore M, Yeatman H, Pollard C. 2013. Evaluating success in public health advocacy strategies. Vietnam Journal of Public Health 1(1):66-75.

Ogden J, Morrison K, Hardee K. 2013. Social capital to strengthen health policy and health systems. Health policy and planning. 29(8):1075-1085.

Richards Z, Thomas SL, Randle M, Pettigrew S. 2015. Corporate Social Responsibility programs of big food in Australia: a content analysis of industry documents. Australian and New Zealand Journal of Public Health. 39(6):550-556.

Rosenberg NJ, Siegel M. 2001. Use of corporate sponsorship as a tobacco marketing tool: a review of tobacco industry sponsorship in the USA, 1995-99. Tobacco control. 10(3):239246.

Sadler GR, Lee H-C, Lim RS-H, Fullerton J. 2010. Recruitment of hard-to-reach population subgroups via adaptations of the snowball sampling strategy. Nursing and Health Sciences. 12(3):369-374.

Saloojee Y, Dagli E. 2000. Tobacco industry tactics for resisting public policy on health. Bulletin of the World Health Organization. 78(7):902-910.

Smith KE, Stewart EA. 2017. Academic advocacy in public health: disciplinary 'duty' or political 'propaganda'? Social Science \& Medicine. 189:35-43.

Stuckler D, Nestle M. 2012. Big food, food systems, and global health. PLoS Medicine. 9(6):e1001242.

Thomas SL, David J, Randle M, Daube M, Senior K. 2015. Gambling advocacy: lessons from tobacco, alcohol and junk food. Australian and New Zealand Journal of Public Health. 40(3):211-217.

Thomas SL, Pitt H, Bestman A, Randle M, McCarthy S, Daube M. 2017. The determinants of gambling normalisation: causes, consequences and public health responses. Melbourne,

Victoria: Victorian Responsible Gambling Foundation (in press).

Vale P, Karataglidis S. 2016 Pressure to publish is choking the academic profession. The Conversation. https://theconversation.com/pressure-to-publish-is-choking-the-academicprofession-62060.

Weishaar H, Collin J, Amos A. 2016. Tobacco control and health advocacy in the European Union: understanding effective coalition-building. Nicotine and Tobacco Research. 18(2):122-129. 
910 World Health Organization. 2003. WHO Framework Convention on Tobacco Contorl

911 Geneva, Switzerland World Health Organization

912

913 Yazahmeidi B, Holman CD. 2007. A survey of suppression of public health information by 914 Australian governments. Australian and New Zealand Journal of Public Health. 31(6):551915 557. eng. 
918 Developing public health advocacy responses to reduce and prevent gambling

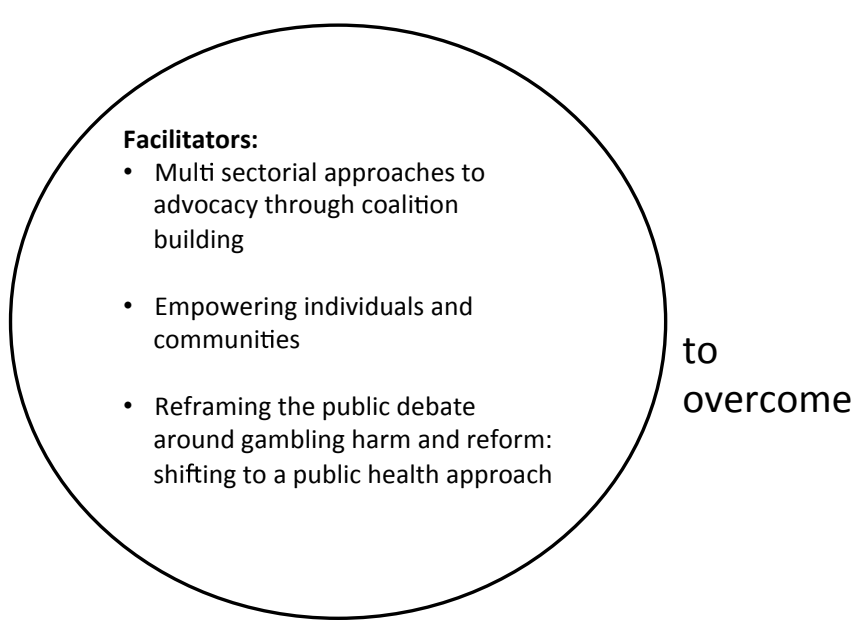

that enable

921

Effective advocacy responses to gambling harm reduction and prevention:

- Addressing stigma

- Enabling community participation

- Creating alternative funding to challenge conflicts of interest

- Developing consistent advocacy strategies through social capital and coalitions

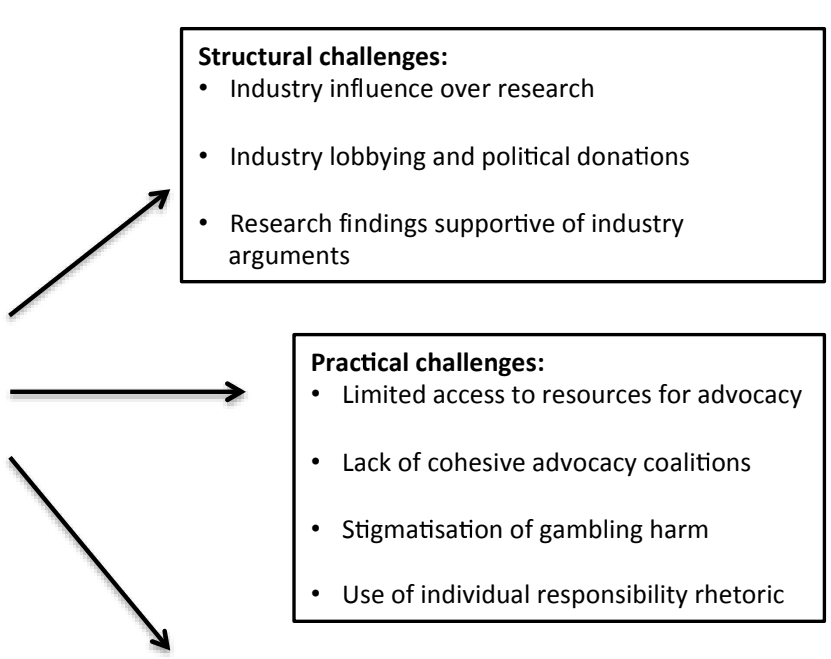

Ideological challenges:

- Different understandings about what constitutes advocacy

- Distinction between advocacy and direct personal activism

- Role of academics/ researchers 